\title{
A Half-Century of Social Work Research: Advances and New Challenges
}

\begin{abstract}
Allen Rubin
Abstract: This article provides an autobiographical account of the evolution and role of social work research since the beginning of my career as a social worker in the late 1960s. It traces the bumpy road from the days when the profession's attitude about research was, at best, ambivalent to today's emphasis on evidence-informed practice and empirically supported treatments. It ends by identifying several new challenges and their implications for future efforts to help further bridge the gap between research and practice in social work.
\end{abstract}

Keywords: Social work research, evidence-informed practice, empirically supported treatments, bridging the research-practice gap

By the time this special issue appears in print, it will be almost a half a century since I was earning my MSW degree and beginning my career as a professional social worker. In discussing the evolution and role of research within the profession over these many years, it might help to begin with some of the research-related experiences I had at the start of my career - things that moved me to change from being exclusively a practitioner to pursuing a research focus in my career. Those were the days when social workers and other mental health practitioners still embraced the notion that dysfunctional family dynamics and schizophrenogenic mothers were the prime and perhaps only cause of all mental illnesses, including psychotic disorders.

\section{Years of Absurdity}

In my first job as a social worker - in a community mental health program - I received in-service training in family therapy. The trainers were fond of saying things like, "There are no crazy people, only crazy families," and "do not focus on any individual as the patient, just the family." One of the published articles that my cotrainees and I were assigned to read was a case report written by a famous family therapist which focused on an incident in which the author wrote his initials on the shoes of a patient suffering from schizophrenia. He claimed that doing so was at least partially curative because by doing something absurd himself he helped the patient gain insight as to the absurdity of her own behavior. Huh?!

I wanted to believe what I read and become an effective therapist, but I could not get over my skepticism about it all and my sense that even if I accepted the ideas I was "learning," I was not receiving enough specific guidance as to how to incorporate these things in my own practice. Should I write $A R$ on the shoes of my clients? Should I engage in other absurd behavior with them? Should I continue to try to get the parents of children with emotional problems to realize that the root of the child's problem lay in their relationship with each other or in the way one or more of them related to their child, especially since my doing so did not seem to be helping the child?

Allen Rubin, Ph.D., holds the Kantambu Latting College Professorship for Leadership and Change at the University of Houston Graduate College of Social Work in Houston, TX.

Copyright @ 2014 Advances in Social Work Vol. 15 No. 1 (Spring 2014), 182-195 
My uneasiness with all this was compounded by the in-class behavior of my cotrainees who were accepting without question all that they were being told. After seeing films of family therapy sessions, for example, they sat starry eyed and praised what they had witnessed in the films. Was I the only one in the class who did not get it?

One day at the conclusion of a video I summoned the courage to ask the two prestigious psychiatrist trainers (the social worker trainer was not there that day), "What was the evidence supporting the effectiveness of the therapy sessions we had been watching?” They reacted by asking the rest of the class to discuss the personal dynamics that made me need so much certainty. That did it! I decided to enter the University of Pittsburgh's social work doctoral program so I could learn how to research the effectiveness of all this stuff.

\section{Program Evaluation: An Avant-garde Idea...Really?}

During my doctoral education in social work I was fortunate to take a course taught by Joe Eaton, who at that time was considered a pioneer in program evaluation. I was struck by how avant-garde the notion was thought to be at that time that the outcomes of programs should be evaluated with rigorous research designs. Why, more than six decades after Mary Richmond (1917) advocated the need for practice to be guided by research, was this notion considered to be avant-garde?! I was also struck by the lack of content in the course on overcoming the obstacles to being able to get practitioners and administrators to permit rigorous outcome studies to be implemented and successfully completed (without bias) in their real world practice settings. (I will return to this latter point shortly.)

\section{Joel Fischer and Gerard Hogarty: Two Evidence-Based Pioneer Provocateurs}

Those were the days when Joel Fischer jolted the social work profession with his provocative research review in Social Work suggesting that social casework was not effective (Fischer, 1973). To many in our profession, at least those who did not want facts to get in the way of their cherished beliefs and vested interests, Fischer was a pariah. But his review was backed up by several other reviews with similar conclusions (Wood, 1978). Slowly but surely, the profession began to learn about the need for critical thinking and questioning about the evidence supporting our beliefs and interventions, and realizing that being on the side of the angels was not enough - we needed to find out if our altruistic efforts were actually helping people.

In fact, thanks to emerging outcome studies, the profession began to learn that sometimes our efforts - despite our best intentions - were harmful. Perhaps the most influential social work researcher at that time whose work alerted the profession to this notion was Gerard Hogarty. Although Hogarty's highest degree was his MSW (he never pursued doctoral education), he had been completing rigorous randomized control trials (RCTs) - well funded by NIMH - on the impact of social casework and psychotropic medication on the course of schizophrenia. He found that when the casework was 
provided without medication, relapse was hastened. But when it was combined with medication, it helped (Hogarty, 1979).

Given what we know now about the biological basis of schizophrenia, Hogarty's results might seem expectable and maybe even humdrum. But in those days many really believed that medication might not be needed and that psychosocial interventions might be sufficient. Thus, learning that psychosocial intervention when provided alone might not only be insufficient, but actually harmful to people with schizophrenia, was quite an eye opener. Hogarty followed those studies up with rigorous RCTs showing that also harmful to clients with schizophrenia were interventions based on the notion that schizophrenia was rooted in faulty family dynamics. His research showed that to be helpful, we need to provide psychoeducational interventions that support families and help them learn how to cope with their relative's biologically based disorder - rather than blame them for the disorder (Anderson, Reiss, \& Hogarty, 1986).

\section{A Bumpy Road}

Given our current evidence-based practice (EBP) era, we have come a long way in the four decades since Hogarty's research impacted the way we help people suffering from schizophrenia and the people who love them and care for them. But it has been a bumpy transition. Fast forwarding for a moment to 1998, NASW convened a national summit meeting with the purpose of uniting the diverse elements of our profession and identifying what issues and priorities social work organizations could agree upon. Despite that unification purpose, in the Summit's keynote speech one of our profession's most renown scholars said that he is "insulted" by the notion that we need to research the outcome of our efforts to provide care (Rubin, 1999).

Returning to in the early 1970s, as I was completing my doctoral education on a parttime basis I got to know and briefly work with Gerry Hogarty when he accepted a position at the psychiatric institute that I would soon leave after completing my coursework. I was in awe of his work and felt I needed to get a lot more experience doing research before I deserved to teach it. But in seeking a career as a program evaluator, I found that nobody who wanted to hire me wanted me to carry out rigorous, unbiased studies that might not reflect well on the impact of their agency. Instead, they wanted "program evaluators" whose "evaluations" would merely focus on crunching and massaging data to portray their agency in a favorable light.

Thus, my interest was piqued when my dissertation chair alerted me to a new position announcement from the Council on Social Work Education (CSWE) to work on a NIMHfunded national research project evaluating the ways in which schools of social work were implementing their NIMH-funded community mental health curricula. The research purpose of the study attracted me to the position, but another attractive feature was that the position would help me learn whether I wanted to pursue a career in academia while giving me the research experience to feel more qualified to teach research. Thus, I was delighted to be offered and to accept the position (although the prospect of moving from Pittsburgh to New York was quite daunting. Had I known that in 1977 I would end up 
living a block away from the Son of Sam serial killer in Yonkers, I guess it would have been significantly more daunting and with a strong effect size!)

Among the many things I learned from that experience pertained to the politics of program evaluation. A main conclusion of my study was that many schools of social work were merely using the NIMH funds to increase their budgets without adding much community mental health content to their curricula. To my naïve surprise, the staff at NIMH did not want to hear that their funds were not achieving their aims because they feared that if some members of Congress were to read my report they would cut their funding for social work education. I had to soften the wording of my report in order for it to be published (Rubin, 1979).

\section{A Landmark Project and Two Landmark Conferences}

At the conclusion of that project, CSWE assigned me to an NIMH-funded project on research utilization. As I began to work on that project, I read emerging studies showing that social workers rarely examined research studies as a basis for informing their practice. Instead, they preferred to be guided by professional consensus and the practice wisdom of respected consultants, supervisors, and revered clinical gurus (Casselman, 1972; Kirk \& Fischer, 1976; Kirk, Osmalov, \& Fischer, 1976; Rosenblatt, 1968).

I also learned that an extreme research-practice gap existed in social work education as well. Research content was isolated in research courses and not being infused in other parts of the curriculum. Practice courses, for example, were being taught without content on the empirical support (or lack thereof) for the practice methods and interventions being taught. Practice instructors typically made little to no effort to show how research can and should inform practice decisions.

The gap, however, existed not only in other parts of the curriculum, but also in the research curriculum itself. Research courses were being taught in ways that had little relevance to practice and consequently little relevance to students, who took research courses only because they were required to do so. The research methods textbooks used in those courses typically were written by scholars from other disciplines, such as sociology, and contained very little in the way of social work illustrations and examples and were devoid of social work practice applications. In fact, social work research courses often were taught by faculty members from other (social science) departments.

What I learned and did on that project had a profound impact on my career as a social work researcher and educator - both in terms of the way I teach research and in the way I write about it. For example, it influenced me to write a research methods textbook loaded with social work research applications and social work practice applications. At the time of this writing that book is in its eighth edition and continues to be widely required in social work research courses (Rubin \& Babbie, 2013). I have long appreciated the feedback I have received regarding the book's impact in making social work research more relevant to students.

One of the ways in which the project attempted to alleviate the research-practice gap in social work education was by convening a national conference and several regional 
conferences on research utilization. Around the same time, in 1978, the National Association of Social Workers (NASW) held a national conference on "The Future of Social Work Research," which also intended to bridge the gap through a dialogue between leaders in social work research (who primarily worked in academia) and leaders from the social work practice community (Fanshel, 1980). The attendees at these conferences developed strategies and tactics for bridging the gap between research and practice in the social work practice community as well as in social work education. By and large, the most emphasized recommendations pertained to the key features of the empirical clinical practice movement, which emerged in social work soon after the completion of the two national conferences.

\section{The Empirical Clinical Practice Movement}

A major aim of the empirical clinical practice movement was to bridge the gap between research and practice in social work education as well as in social work practice by providing students and practitioners with research tools and designs that they could use as part of their practice and to enhance their practice effectiveness. In fact, the movement provided a new social work practice model. Called the empirical clinical practice model, it contained two major components: 1) employing single-case designs to idiographically evaluate one's own effectiveness with each case; and 2) making practice decisions in light of the research evidence that can inform those decisions.

Of the above two key components of the model, the first - regarding single-case designs - received the most attention and stirred the most controversy. At that time, proponents of the model expressed a great deal of optimism that these designs would provide practitioners with a research tool that they would find feasible and useful. Some schools of social work developed research courses devoted to these designs, while others revised their existing research courses to increase the amount of emphasis on these designs. Several textbooks emerged devoted primarily to the use of these designs. However, the results of these efforts were disappointing. Study after study found that social work practitioners who graduated from programs that emphasized the empirical clinical practice model rarely utilized single-case designs in their practice. Those who wrote about this disappointing outcome at the time - mainly during the late 1980s and early 1990s - seemed to agree that the main reasons why more practitioners weren't using those designs had to do with a lack of agency resources - especially regarding caseload sizes and time - necessary to implement the designs and a lack of administrative and supervisory support and incentives for implementing them (Kirk \& Reid, 2002).

\section{SSWR, IASWR, and the Task Force on Social Work Research}

Three other developments that occurred during the latter years of the $20^{\text {th }}$ century impacted the way social work research is practiced and taught today: the emergence of the Institute for the Advancement of Social Work Research (IASWR); the birth and growth of the Society for Social Work and Research (SSWR); and the federal funding of the Task Force on Social Work Research. Those developments were interrelated in that they supported each other and attempted to improve the social work research enterprise especially as defined by an increase in federal research grant applications. 
The IASWR was born with seed money from the Ford Foundation and from the National Institute of Mental Health (NIMH). Its main mission was to implement efforts to enhance the preparedness and inclination of social work faculty members and doctoral students to conduct rigorous research and compete for research grants from federal funding sources. The IASWR lasted for about a decade before funding losses caused its demise. One reason for those funding losses was the success of SSWR, which eventually duplicated the efforts of IASWR.

At the same time that NIMH provided seed money for IASWR it provided seed money for the birth of SSWR, which became the first professional membership organization for social work researchers per se. As a charter member of SSWR - as well as its second vice president, third president, and later board member - I observed the way it grew and evolved.

SSWR was born at a small charter conference held in Washington, DC in 1994. Two years after that conference some of my colleagues and I wondered whether it still existed. I learned that it did still exist upon receiving a phone call from a dear colleague, Tony Tripodi, asking if I would support his nomination to become its second president, succeeding its first president and SSWR founder: Janet Williams. I enthusiastically agreed to do so. Shortly after that I received another phone call, this one from a SSWR board member asking me to agree to be the other nominee for SSWR president. I declined, noting that I had already promised Tony that I would support him. The caller then asked if I would agree to be nominated to run for the vice presidency, and to that I agreed.

One of my key influences on the growth of SSWR was to persuade Tony and other board members that if the organization was to survive and grow, it needed to convene an annual SSWR conference. During the next three years, several of my colleagues on the SSWR board and I volunteered an enormous amount of time and effort in pulling off these annual conferences, which turned out to be huge successes in building the financial base enabling SSWR to become what it is today. By the end of the 1990s, its membership had quadrupled from its initial 250 charter members, and the registration fees from its conferences provided the resources for later board members to hire professional conference planners to do the work that we had volunteered during SSWR's early years.

As SSWR's membership grew and became more diverse, so did its mission. Instead of focusing primarily on an opportunity for social work researchers to share their works, it became more and more like the CSWE annual conferences. For example, at the early SSWR conferences, the focus was exclusively on attending the session presentations. Today, however, many of the hundreds of attendees are doctoral students seeking faculty positions and deans and faculty members who focus much of their time at the conference on scouting and interviewing prospects for faculty positions.

Another way in which SSWR evolved was to increase its efforts to duplicate (and eventually replace) IASWR efforts to promote federal funding of social work research grant applications and to increase the number of such applications being submitted by social workers. During SSWR's early years during the 1990s these efforts were enhanced by the work of an NIMH-funded Task Force on Social Work Research, chaired by David 
Austin. As David's faculty colleague at the time, and in my leadership roles in SSWR, I was kept well informed of the Task Force's efforts.

One of the Task Force's successes was in promoting the NIMH funding of research development centers in a handful of prestigious schools of social work. By improving the research infrastructure in those schools, NIMH and the task force sought to increase the submission of competitive mental health research grant proposals from social work researchers. Today we see an increased submission of such proposals from social work faculty members, especially from those in Research 1 universities. It is debatable, however, whether the impetus for this increase came primarily from the work of the above NIMH-funded efforts versus the increased pressure from university administrators on deans of schools of social work to bring in more research funding. I suspect that the latter pressure had the greater impact, especially when I hear about some deans today telling their junior faculty that securing a well-funded research grant is a prerequisite for getting tenured. In my opinion, this trend has a downside to which I shall return in the final section of this article.

\section{The EBP Movement and Empirically Supported Treatments (ESTs)}

I am going to assume that the readers of this issue already are familiar with concept of EBP and don't need me to go over its definition and procedural steps. Instead, I will discuss it in terms of its implications for the focus of this article: advances and emerging challenges in social work research. I'll consider the advances first.

The EBP movement has influenced the nature of social work education and practice. In several surveys that I conducted pertaining to EBP, my coauthor Danielle Parrish and I found grounds for optimism that more and more social work educators and practitioners these days favor the notion that professional practice decisions should be informed by scientific evidence (Parrish \& Rubin, 2012; Rubin, 2007; Rubin \& Parrish, 2007). As one outcome of a national symposium that I organized and led in 2006 on improving the teaching of EBP, CSWE increased its emphasis on EBP in its educational and policy accreditation standards (Rubin, 2007).

One of the foci of that conference was the need to distinguish between EBP and ESTs. The former is a process for the purpose of having one's practice informed by empirical evidence. The latter is a type of empirical evidence that one may find.

The emphasis we see today among funding sources and agencies regarding developing and selecting policies, programs and interventions based on their empirical support (often in the form of ESTs) suggests that we have come a long way since the start of my career, when my asking an instructor about evidence prompted him to question my neediness!

These are indeed exciting times! Rigorous systematic reviews and meta-analyses including but not limited to those sponsored by the Cochrane and Campbell Collaborations - are making it easier for practitioners to be guided by research supporting the effectiveness of programs and interventions for more and more problems that 
confront social workers and other helping professionals. Some of the programs and interventions with at least promising empirical support are as follows:

- For adults with PTSD or other anxiety-related disorders we have Prolonged Exposure Therapy, Cognitive Processing Therapy, and EMDR

- For traumatized children we have Trauma-Focused Cognitive Behavior Therapy (TFCBT)

- For substance use disorders we have Motivational Interviewing, Cognitive Behavioral Skills Training, and Seeking Safety

- For borderline personality disorders there is Dialectical Behavioral Therapy

- For people with schizophrenia or their families we have Psychoeducational Family Groups, Cognitive Behavioral Therapy, Assertive Community Treatment, Supported Employment, and Critical Time Intervention

- For families at risk for child maltreatment there are programs like The Incredible Years, Parent-Child Interaction Therapy, and Triple-P

- $\quad$ For depression we have Interpersonal Therapy and CBT

Information about many of these interventions is now available at the click of a mouse, as many intervention manuals and support materials are provided online. Moreover, practitioners no longer have to go to a university library to obtain access to books or journal articles - almost all of this information is available remotely at one's home or office on various websites and public libraries. In addition, I have co-edited a series of volumes summarizing the evidence-base for these programs and interventions as well as guidelines for practitioners who want to employ them (see, for example, Rubin, Springer, \& Trawver, 2010).

\section{New Challenges: Implementation Science}

Despite the great strides that have been made regarding evidence-based practice and the promising implications of those strides for bridging the gap between research and practice, however, the gap is still wide. Various studies have found that ESTs often are being implemented inappropriately and with unsuccessful outcomes in the real world practice of social work and allied professions (Embry \& Biglan, 2008).

The emerging field of implementation science is developing recommendations for alleviating this problem by studying factors associated with whether ESTs are implemented properly and with good outcomes. For example, some of the recommendations include utilizing respected peer opinion leaders to persuade practitioners as to the value of implementing the EST and providing ongoing coaching to help maintain the practitioner enthusiasm and self efficacy regarding the EST (Damschroder et al., 2009; Embry \& Biglan, 2008; Glisson \& Schoenwald, 2005; Weisz, Ugueto, Herren, Afienko, \& Ruff, 2011). One challenge for the future of social work research involves conducting studies to learn more about such factors - especially in real world social work practice settings. I'll return to this issue later. 


\section{New Challenges: Common Factors}

A school of thought has emerged in recent years that argues that engaging in the EBP process to try to select ESTs is a waste of time because common factors, such as the relationship skills of the practitioner and the quality of the treatment alliance, have a much greater impact on treatment outcome than does the choice of intervention. In its extreme form, this argument is referred to as the dodo bird verdict (from Alice in Wonderland), in which all are winners. The dodo bird verdict argues that the choice of intervention has no bearing whatsoever on treatment outcome.

One problem with the dodo bird verdict is that it is based on a controversial metaanalysis (Wampold, 2001) that has been criticized for its methodology and has not been supported by some other meta-analyses (Beutler, 2002; Craighead, Sheets, \& Bjornsson, 2005; Lilienfeld, 2007). A less extreme form of the common factors argument maintains that the choice of intervention has some impact on outcome, but its impact is much weaker than the impact of common factors (Graybeal, 2007).

Although I am skeptical about the dodo bird argument and its more moderate version, I believe that we need more research on this issue to settle the argument. For the time being, however, we should recognize that the either/or argument of common factors versus choice of intervention is a false dichotomy. As is evident in every EST treatment manual that I have examined, a good therapeutic alliance is emphasized as a prerequisite for an EST's success. Indeed, every one of these manuals identifies establishing a good treatment alliance as an important and necessary component of the EST itself! Thus, recognizing the importance of common factors need not demean the importance of choice of intervention.

\section{New Challenges: Common Elements}

Another emerging line of inquiry involves identifying the core essential and indispensible elements of each EST as well as their adaptable elements. The purpose of doing so is to give practitioners more flexibility to make the EST fit their organization and clientele and also reduce the costs of practitioner training (Galinsky, Fraser, Day, \& Rothman, 2013; Sundell, Ferrer-Wreder, \& Fraser, 2012). Part of the rationale for the common elements approach is the recognition that even when ESTs are implemented with good fidelity, they often have unsuccessful outcomes because the EST's ideal treatment conditions and relatively homogeneous clientele differ significantly from the far less than ideal treatment conditions and very diverse clientele in real world practice settings (Weisz et al., 2011).

Although the common elements approach holds promise for improving the effectiveness of social workers in real world practice settings, it also poses some risks. For example, two intervention approaches with substantial empirical support for treating trauma symptoms are exposure therapy and cognitive processing therapy. And yet, in a meta-analysis aimed at identifying the common elements for effectively treating "disruptive behavior and traumatic stress among adolescent girls," Bender and Bright (2011) omitted any mention of those two approaches in their identification of eight common elements in which practitioners working with such girls should be trained. 
Instead, they recommended only that practitioners be trained in: goal setting, monitoring, communication skills, praise, problem solving, psychoeducation with parents, social skills training, and tangible rewards.

In seeking to understand how these two capable researchers could have made such an important omission, I surmise it is because of the broadness of their search boundaries. By combining disruptive behaviors with traumatic stress in their search, the proportion of the 430 RCTs they reviewed that dealt with disruptive behavior only perhaps far outweighed the proportion of RCTs that focused exclusively on traumatic stress. That would explain why the eight common elements that they identified appeared much more frequently, across far more studies, than the ESTs for traumatic stress. (I surmise that there are far more ESTs on behavioral interventions for various behavior problems than there are for traumatic stress only.)

Consequently, I recommend in our future research on common elements that we keep the search boundaries narrow, such as limiting the search to a single EST and looking at what elements of the EST need to be kept across different practice settings and target clientele, which elements can be adapted, and which (if any) elements need not be kept at all. Or we might aim to identify the common elements across a few ESTs that target the same problem. But to the extent that we broaden the number of ESTs and target problems in our search we risk omitting some important intervention approaches from our list of the elements that appear most frequently in the studies we find.

\section{New Challenges: An Inductive Strategy for Researching Adaptations of ESTs in Real World Social Work Practice Settings}

Earlier I mentioned the need to study factors associated with whether ESTs are implemented with fidelity and good outcomes in real world social work practice settings. However, as suggested above, even when ESTs are implemented with fidelity in real world settings their outcomes might be disappointing because the ideal RCT conditions under which they gained their research support may have limited transferability to real world social work practice settings. In those RCTs, their effectiveness typically is assessed with the intervention being provided by practitioners who are well trained and closely supervised - perhaps by those who developed the intervention and their key associates - and who have small caseload sizes and relatively homogeneous clientele. Expensive training and expensive supervision - as well as low caseload sizes with homogeneous clientele - are likely to be infeasible and unaffordable in most real world social work practice settings.

Therefore, we need to investigate the conditions under which adaptations of ESTs in real world social work settings are and are not effective. We need to assess variability in outcome associated with such variables as:

- How ESTs are tweaked to fit the setting

- Clientele and practitioner characteristics

- Nature of training and supervision 
- Agency resources and other characteristics (including caseload sizes)

Given the significant practical obstacles, it is hard to imagine using RCT designs to conduct such investigations in real world social work practice settings. However, control group designs might not be necessary to investigate those associations because threats to internal validity have already been ruled out in the RCTs that provided the empirical support for the ESTs. Moreover, a study need not meet all of the criteria for establishing causality to have value in supporting the plausibility of a causal hypothesis. Moreover, if various pretest-posttest studies, without control groups and conducted at different points in time, show that when an EST is adapted in a similar way a desirable outcome follows, then the plausibility that history is the real cause of the outcome is reduced.

Therefore, I urge social work researchers to conduct such studies (after connecting with agencies interested in or already adapting an EST in their setting). Such studies do not require large sample sizes or major funding. For example, I have been able to conduct similar studies with virtually no funding as long as the agency agrees to have clients complete self-report pretests at intake and termination of treatment. To limit social desirability bias, the clients would complete their self-reports without their practitioner seeing their answers. The researchers could couple the client self-report results with a descriptive case study of agency and practitioner characteristics, how the EST was adapted, and the nature of the training and supervision practitioners received in the adapted intervention.

As such studies are published over time, an inductive process could be employed to develop and test hypotheses about the conditions under which ESTs can be adapted so that they are more feasible and more effective when provided in real world practice settings. I urge social work research journals (such as Research on Social Work Practice) to encourage researchers to conduct and submit such studies, with the assurance that if they conduct the kind of case study I have described above, a control group would not be a necessary prerequisite for publication. I believe that this would be a sufficient incentive - especially in institutions where obtaining major research funding is not a prerequisite for earning tenure or promotion.

I also urge social work faculty and deans in Research 1 universities to try to enlighten their university administrators as to the value of such studies and to the unique and valuable contribution that social work can make in conducting them. If faculty members can be successful in getting major research funding, then pursuing my recommended strategy may not be in their best interest. But how many junior faculty members in Research 1 universities are now devoting their precious tenure-earning years writing, submitting, rewriting, and resubmitting proposals that may never be funded? Although I am not disparaging the value of obtaining major research funding, I would like to see pursuing the strategy that I am recommending as an additional way to gain tenure and promotion. If only we can overcome the dollar signs in the eyes of university administrators who so often today perceive fund raising as the most important criterion regarding how their own performance will be evaluated. 


\section{References}

Anderson, C. M., Reiss, D. J., \& Hogarty, G. E. (1986). Schizophrenia and the family: A practitioner's guide to psychoeducation and management. New York, NY: Guilford Press.

Bender, K., \& Bright, C. L. (2011, January 13). A review of common elements of effective interventions for reducing disruptive behavior and traumatic stress among adolescent girls. Paper presented at the annual conference of the Society for Social Work and Research, Tampa, FL.

Beutler, L. E. (2002). The dodo bird is extinct. Clinical Psychology: Science and Practice, 9, 30-34.

Casselman, B. (1972). On the practitioner's orientation toward research. Smith College Studies in Social Work, 42, 211-233.

Craighead, W. E., Sheets, E. S., \& Bjornsson, A. S. (2005). Specificity and nonspecificity in psychotherapy. Clinical Psychology: Science and Practice, 12(2), 189-193.

Damschroder, L. J., Aron, D. C., Keith, R. E., Kirsh, S. R., Alexander, J. A., \& Lowery, J. C. (2009). Fostering implementation of health services research findings into practice: A consolidated framework for advancing implementation science. Implementation Science. Retrieved from http://www.implementationscience.com/content/4/1/50

Embry, D. D., \& Biglan, A. (2008). Evidence-based kernels: Fundamental units of behavioral influence. Clinical Child and Family Psychology Review, 11, 75-113.

Fanshel, D. (Ed.). (1980). Future of social work research. Washington, DC: NASW.

Fischer, J. (1973). Is casework effective? A review. Social Work, 18, 5-21.

Galinsky, M., Fraser, M. W., Day, S. H., \& Rothman, J. M. (2013). A primer for the design of practice manuals: Four stages of development. Research on Social Work Practice, 23(2), 219-228.

Glisson, C., \& Schoenwald, S. K. (2005). The ARC organizational and community intervention strategy for implementing evidence-based children's mental health treatments. Mental Health Services Research, 7(4), 243-259.

Graybeal, C. T. (2007). Evidence for the art of social work. Families in Society, 88(4), 513-523.

Hogarty, G. (1979). Aftercare treatment of schizophrenia: Current status and future direction. In H. M. Pragg (Ed.), Management of schizophrenia (pp. 19-36). Assen, Netherlands: Van Gorcum.

Kirk, S. A., \& Fischer, J. (1976). Do social workers understand research? Journal of Education for Social Work, 12, 63-67.

Kirk, S. A., Osmalov, M., \& Fischer, J. (1976). Social workers' involvement in research. Social Work, 21, 121-124. 
Kirk, S. A., \& Reid, W. J. (2002). Science and social work practice. New York, NY: Columbia University Press.

Lilienfeld, S. O. (2007). Psychological treatments that cause harm. Perspectives on Psychological Science, 2(1), 53-70.

Parrish, D., \& Rubin, A. (2012). Social workers' orientation to evidence-based practice: A comparison with psychologists and LMFTs. Social Work, 57, 201-210.

Richmond, M. E. (1917). Social diagnosis. New York, NY: Russell Sage Foundation.

Rosenblatt, A. (1968). The practitioner's use and evaluation of research. Social Work, 13, 53-59.

Rubin, A. (1979). Community mental health in the social work curriculum. New York, NY: Council on Social Work Education.

Rubin, A. (1999). Presidential editorial: A view from the summit. Research on Social Work Practice, 9(2), 142-147.

Rubin, A. (2007). Epilogue: The Austin initiative. Research on Social Work Practice (Special Issue on Evidence-Based Practice), 17(5), 630-631.

Rubin, A., \& Babbie, E. R. (20013). Research methods for social work ( $8^{\text {th }}$ ed.). Belmont, CA: Cengage.

Rubin, A., \& Parrish, D. (2007). Challenges to the future of evidence-based practice in social work education. Journal of Social Work Education, 43(3), 405-428.

Rubin, A., Springer, D. W., \& Trawver, K. (Eds). (2010). Psychosocial treatment of schizophrenia. Hoboken, NJ: John Wiley \& Sons, Inc.

Sundell, K., Ferrer-Wreder, L., \& Fraser, M. W. (2013). Going global: A model for evaluating empirically supported family-based interventions in new contexts. Evaluation \& the Health Professions. Retrieved from http://ehp.sagepub.com/content/early/2013/01/03/0163278712469813.full.pdf+html

Wampold, B. E. (2001). The great psychotherapy debate: Models, methods, and findings. Mahwah, NJ: Erlbaum.

Weisz, J. R., Ugueto, A. M., Herren, J., Afienko, S. R., \& Ruff, C. (2011). Kernels vs. ears and other questions for a science of treatment dissemination. Clinical Psychology: Science and Practice, 18(1), 41-46.

Wood, K. M. (1978). Casework effectiveness: A new look at the research evidence. Social Work, 23(6), 437-458.

\section{Author note}

Address correspondence to: Allen Rubin, Ph.D., Kantambu Latting College Professorship for Leadership and Change, University of Houston Graduate College of Social Work, 110HA Social Work Building-Room 342, Houston, TX 77024-40.

Email: arubin2@central.uh.edu 


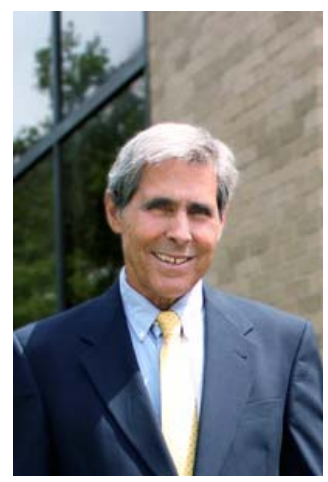

Allen Rubin, Ph.D., is the Kantambu Latting Professor for Leadership and Change at the University of Houston Graduate College of Social Work. His approximately 150 publications have focused on research methods, statistics, severe and persistent mental illness, trauma treatment, evidence-based practice, and other areas. A founding member of the Society for Social Work and Research (SSWR), he served as its president from 1998 to 2000. His awards include the University of Pittsburgh, School of Social Work's Distinguished Alumnus Award (1993), the SSWR Award for Outstanding Examples of Published Research (1997), the CSWE Significant Lifetime Achievement in Social Work Education Award (2007), and Fellow of the American Academy of Social Work and Social Welfare. 